\title{
Goal-Awareness and Goal-Adaptive Information Presentation to Support Collaborative Learning in Informal Settings.
}

\author{
Eva Mayr, Virtual PhD Program, Konrad-Adenauer-Str. 40, 72072 Tuebingen, Germany, e.mayr@iwm-kmrc.de
}

\begin{abstract}
This dissertation explores the use of adaptive technology for more goal-oriented learning in informal settings like museums or web sites. Visitors usually do not give priority to learning and knowledge building. It is assumed that information presentation should be adaptive and match visitor dyads' shared interests to enhance collaborative elaboration on presented information in these settings. During collaborative exploration of a site, awareness of shared goals and goal-oriented knowledge communication should further enhance learning. To address these questions two empirical studies are conducted. Exhibit information is presented adaptively to visitor dyads' shared interests during their visit to a virtual (study 1) and a real museum (study 2). Impact on visitors' conversation, behavior and learning can provide further perspectives for future research and provide deeper insights on collaborative knowledge processing and on design of technology in informal settings.
\end{abstract}

\section{Theoretical framework}

Informal learning settings like museums or web sites provide rich resources for individual and collaborative knowledge building: Visitors can choose from a huge pool of information according to their personal interest (free-choice-learning, Dierking, Ellenbogen, \& Falk, 2004). Therefore, visitors' interests and learning goals have an even greater impact in informal than in formal learning settings (Boekaerts, \& Minnaert, 1999). For example, they guide information selection, evaluation of and elaboration on information during a visit. Unfortunately, informal learning is often inferior to formal learning with regard to knowledge acquisition. This seems to be due to two different facts: A lack of goal-orientation and a reduced amount of invested mental effort.

First, as museums are leisure settings many visitors come without any or without concrete learning intentions in mind (Black, 2005; Packer, 2006). However, different amounts of knowledge are gained by visitors with different visiting intentions (Falk, Moussouri, \& Coulson, 1998; Packer, 2006). Visitors with a focused visiting strategy learn more from their museum visit (Falk et al., 1998). Therefore, learning could be improved when a museum is visited in a more focused way. Studies in formal learning contexts showed the relevance of goals for more strategic information processing (e.g., Zumbach, \& Reimann, 2002). Conscious goals are available in working memory and have a high potential to structure information processing (Austin \& Vancouver, 1996). Additionally, aware goals can raise curiosity, intrinsic motivation and attention towards reaching this goal (Boekarts, \& Minnaert, 1999; Csikszentmihalyi, \& Hermanson, 1995; Loewenstein, 1994). Therefore making goals aware to visitors prior to a museum visit might enhance their goal orientation and thereby informal learning.

Second, people invest less mental effort in leisure settings than in formal learning settings (Salomon, 1984). Additionally, visitors' attention decreases with visiting time (Serrell, 1997). But due to lack of structure and pre-selection of information, informal settings often require even more mental resources to process information thoroughly (Boekaerts, \& Minnaert, 1999). For example, advanced organizers (Falk, 1997) or conversation with others (Leinhardt, Crowley, \& Knutson, 2003) can help visitors to process information in informal settings. But these actions do not serve all visitors in the same way: They have different interests, prior knowledge, and time resources. New media applications can adapt information to visitors' needs. An exemplary museum application is a PDA guide suggesting tours based on visitors' interests and time budget (Teo, 2005). As information that matches visitors' interests reduces the amount of mental effort needed, more cognitive capacities are available to process the information. Thereby, informal learning could be increased.

Descriptive museum studies (e.g., Black, 2005, p. 16) show that about $80 \%$ of museum visitors come in groups. Co-visitors influence knowledge processing in the museum (Packer, \& Ballantyne, 2005): Dyads share opinions about the exhibits, explain them to each other and relate information to prior shared experiences in their conversations. Therefore, the social situation can assist knowledge acquisition in the individual (e.g., Hinsz, Tindale, \& Vollrath, 1997) and should be taken into account when designing technological support for informal learning. 


\section{Research Questions}

First, the research question is addressed, whether awareness of a visitor dyad's shared goals influences visitor dyad's goal-orientation during informal learning in a museum. Therefore, visitor dyads in this study are asked to state their shared interests prior to the visit of the exhibition. It is assumed, that increased goal-orientation results in more focused exhibit selection, influences conversation, and gives rise to learning.

Second, it will be investigated whether adaptation of exhibit information to a visitor dyad's shared goals can further support elaboration of information (conversation, exhibit selection) and learning. For this purpose an adaptive technology is used, that provides visitor dyads with adaptive information according to their shared interests on every selected exhibit. This adaptation reduces the requirement to connect selected objects and information with a dyad's shared goal. It is assumed that visitor dyads provided with adaptive information will select objects differently, elaborate information in their conversation in different ways, and finally learn more than visitors provided with non-adaptive information.

A third research question addresses the comparability of different research settings and their impact on validity, reliability, and authenticity of studies on informal learning in museums. An exhibition about nanotechnology ("Nanodialogue" by the European Commission, cp. Nanodialogue Consortium, 2007) serves as research setting in this project. It will be used in three different versions: As a virtual exhibition on the web (study 1: adaptive graphical hypertext), as a physical exhibition in the lab (study 2: adaptive PDA), and as a physical exhibition in the real museum (study 3: adaptive PDA).

\section{Methods}

A 2 (goal-awareness, no goal-awareness) x 2 (adaptive, non-adaptive) experimental design is used in these studies (cp. table 1). 15 dyads of acquaintances per condition are asked to participate in a study on communication in museums (cover story).

\section{Table 1: Research design}

\begin{tabular}{lll}
\hline \multirow{2}{*}{ Goal-awareness } & \multicolumn{2}{l}{ Goal-adaptive Information } \\
\cline { 2 - 3 } & yes & no \\
\hline yes & condition 1 & condition 2 \\
no & condition 3 & control condition \\
\hline & & \\
& &
\end{tabular}

At the beginning, participants are familiarised with navigation in the graphical hypertext (study 1 ) or use of the PDA (study 2). Dyads in the goal-awareness conditions are asked to select a topic of shared interest from a list of topics, which are satisfied in the exhibition. In condition 1, information about the exhibits is adapted to these interests. In condition 3, information about the exhibits is adapted implicitly to a dyad's behaviour in the first minutes of their visit. While dyads visit the virtual exhibition without time constraints, their conversation, exhibit, and information selection is recorded. After the visit participants are asked to fill out a questionnaire on their knowledge, satisfaction, experienced mental effort, prior knowledge, and interest in the topic.

\section{Analyses}

Qualitative and quantitative analyses will be combined in this dissertation: Information selection during the visit will be traced by the PDA's (study 2) or hypertext (study 1) log files and will provide data on the selection of exhibits and information, time spent at exhibits, and overall visiting time. Visitors' dialogues will be analysed with respect to shared goal and information selection, information evaluation, and conversational elaboration.

Comparisons between the four experimental conditions will provide insight into the influence of goalawareness and goal-adaptive information presentation on information selection, conversational elaboration and knowledge acquisition during an informal museum visit. By comparing the laboratory and the virtual museum setting, knowledge is gained about differences in goal-oriented learning in a real-life and a virtual informal setting. Furthermore, both settings will be compared to the real museum setting to ensure external validity of findings gained from the two laboratory experiments. 


\section{Expected Results}

Visitors focused on a specific interest stay longer in a museum (Doering, \& Pekarik, 1997; Falk et al., 1998) and learn more (Falk et al., 1998). By adapting information to visitors' shared interests a deeper processing strategy should be induced. Therefore, it is expected that information is elaborated deeper in dyadic conversation, when information is adapted to their shared interests. Dyads with non-adaptive information should gain broader, but shallower knowledge whereas dyads with adaptive information should acquire more detailed, more elaborated knowledge; this same pattern should show up in the knowledge test. It is assumed that dyads in condition 1 are more satisfied with their visit, need to invest less mental effort, and get more interested in the topic.

\section{References}

Austin, J. T., \& Vancouver, J. B. (1996). Goal constructs in psychology: Structure, process and content. Psychological Bulletin, 120, 338-375.

Black, G. (2005). The engaging museum. London: Routledge.

Boekaerts, M., \& Minnaert, A. (1999). Self-regulation with respect to informal learning. International Journal of Educational Research, 31, 533-544.

Csikszentmihalyi, M., \& Hermanson, K. (1995). Intrinsic motivation in museums: Why does one want to learn? In J. H. Falk \& L. D. Dierking (Eds.), Public institutions for personal learning: Establishing a research agenda. Washington, DC: American Association of Museums.

Dierking, L. D., Ellenbogen, K. M., \& Falk, J. H. (2004). In principle, in practice: Perspectives on a decade of museum learning research (1994-2004). Science Education, 88, 1-3.

Doering, Z. D., \& Pekarik, A. J. (1997). Why time is not quality. Curator, 40, 249-252.

Falk, J. (1997). Testing a museum exhibition design assumption: The effect of explicit labeling of exhibit clusters on visitor concept development. Science Education, 81, 679-687.

Falk, J. H., Moussouri, T., \& Coulson, D. (1998). The effects of visitors' agendas on museum learning. Curator, 41, 107-120.

Hinsz, V. B., Tindale, R. S., \& Vollrath, D. A. (1997). The emerging conceptualization of groups as information processors. Psychological Bulletin, 121, 43-64.

Leinhardt, G., Crowley, K., \& Knutson, K. (Eds.) (2002). Learning conversations in museums. Mahwah, NJ: Lawrence Erlbaum Associates.

Loewenstein, G. (1994). The psychology of curiosity: A review and reinterpretation. Psychological Bulletin, 116, 75-98.

Nanodialogue Consortium (2007). Nanotechnologies and nanosciences: A discussion on ethical, legal and social aspects. Project Summary. Retrieved March 14, 2007, from http://www.mediterraneomarnero.it/nanodialogue/pdf/summary_of_the_project.pdf

Packer, J. (2006). Learning for fun: The unique contribution of educational leisure experiences. Curator, 48, 329344.

Packer, J., \& Ballantyne, R. (2005). Solitary vs. shared learning: Exploring the social dimension of museum learning. Curator, 48, 177-192.

Salomon, G. (1984). Television is "easy" and print is "tough": The differential investment of mental effort as a function of perceptions and attributions. Journal of Educational Psychology, 76, 647-658.

Serrell, B. (1997). Paying attention: The duration and allocation of visitors' time in museum exhibitions. Curator, 40, 108-125.

Teo, J. (2005). ScienceAlive: Wireless, location-based, multimedia PDA tour guide. In S. Hsi (Ed.), Electronic Guidebook Forum (p. 10-14). San Francisco: Exploratorium.

Zumbach, J., \& Reimann, P. (2002). Enhancing learning from hypertext by inducing a goal orientation: Comparing different approaches. Instructional Science, 30, 243-267.

\section{Acknowledgements}

The author is member of the Virtual PhD-Program "Knowledge Acquisition and Knowledge Exchange with New Media" (VGK) sponsored by the German Research Association (DFG). This dissertation is conducted within the wider context of a research project (Knowledge Media Research Center, Tübingen; Deutsches Museum, Munich; Institute for Science Education, Kiel) on learning in the museum with new technologies funded by the "Pact for research and innovation" of the German Federal Ministry of Education and Research. 